\section{Authenticity, Insight, And Impaired Decision-Making CapaCity In ACQuiRed}

\section{BRAIN INJURY}

\section{Gareth S. OWen, FABian FreyenhaGen, \& WAyne Martin}

Thanks to Barton Palmer and John McMillan for these thoughtful commentaries. We found much to agree with and it is striking how so many of the issues relating to decision-making capacity (DMC) assessment find resonances outside of an English jurisdiction. California and New Zealand are clearly grappling with a very similar set of issues and the commentaries speak to the international nature of these discussions.

We will pick up on some main points the commentaries raise.

\section{Authenticity}

As Palmer notes, DMC law is vulnerable to the criticism that it does not attend to the authenticity of a decision. In ordinary language, this is the idea that someone is deciding while "not their self" or that it is the "illness speaking.", There is a tradition of connecting personal autonomy with authenticity in both philosophy and in law. Frankfurt (1971), Dworkin (1976), and Christman (2009) all do this in different ways in their philosophical writing and the English Law Commission started off its consultations on mental capacity by considering the category of "true choice" (The Law Commission, 1995). For good or for bad, the explicit use of authenticity has been avoided by law because of concerns it is vulnerable to idiosyncratic or inconsistent interpretation. How would one know_and reliably demonstrate _ that a choice was "true"? Unconvinced that we have a practicable answer, Law has put weight on decision-making abilities. Critics have objected that this makes the test "too cognitive" or naively committed to "value neutrality" (Charland, 2011). However, tests of DMC are agnostic about the psychological modality of the abilities_for example, whether they are cognitive, emotional, related to will, and so on-with courts given quite a
Copy Editor 1/7/2018 3:24 PM

Deleted: AND

\section{Copy Editor 1/7/2018 3:25 PM}

Formatted: Small caps

\section{Copy Editor 1/7/2018 3:25 PM}

Deleted: st

Copy Editor 1/7/2018 3:25 PM

Deleted:".

\section{Copy Editor 1/7/2018 3:26 PM}

Deleted: (Christman, 2009; Dworkin, 1976; Frankfurt, 1971)

Copy Editor 1/7/2018 3:26 PM

Deleted: -

Copy Editor 1/7/2018 3:26 PM

Deleted: -

Copy Editor 1/7/2018 3:27 PM

Deleted: But

Copy Editor 1/7/2018 3:26 PM

Deleted:

Copy Editor 1/7/2018 3:27 PM

Deleted: e.g.

Copy Editor 1/7/2018 3:27 PM

Deleted: etc.

Copy Editor 1/7/2018 3:26 PM

Deleted: 
margin to interpret the abilities case by case. In addition, any commitment to "value

neutrality" could be reframed as a commitment to value pluralism_especially if "true

choice" is considered at risk of collapsing to "assessor's choice." In a similar vein, DMC

Copy Editor 1/7/2018 3:26 PM

Deleted: -

Copy Editor 1/7/2018 3:25 PM

dovetails better with certain liberal commitments than requiring authenticity the latter is at

Deleted: .

Copy Editor 1/7/2018 3:26 PM

least sometimes interpreted to be so exacting a standard that few will ever meet it, and,

Deleted:

hence, making respect for basic rights depend on authenticity would mean that such respect

would be available only to the few, whereas the commitment of liberal democracy is that it

should be available to the many and withholding it should be exceptional.

Most legal and ethical tests of DMC involve recognition of understanding and communicating abilities and a second set of decision-making abilities that fall into categories of evaluation and deliberation. A central problem facing tests of DMC is adequate specification of the second set. Some clinicians understand the later as 'insight,' but whatever correlations exist, insight is a clinical construct and law will need less clinically centric variables. The English Mental Capacity Act uses the concepts of ability to "use" and "weigh." Before this, English case law referred to ability to "believe" (Re C. 1994). In U.S. jurisdictions, the form "appreciate" and "reason" is often given (Berg, Appelbaum, \& Grisso, 1996). In Scotland it is ability to "act" and "decide" (Adults with Incapacity „Scotland]_Act, 2000).

Our purpose in the study was to select cases where we could learn about what these evaluative or deliberative abilities were by letting patients themselves show us within interview. We selected brain injury because in this group we can find model examples of people whose understanding and communication abilities are not in doubt $_{2}$ but where concerns are often expressed about decision making.

The ability to have online awareness in a decision-making situation we think is shown by these patients as a condition on the possibility of DMC. We think it can be satisfactorily interpreted__in Mental Capacity Act terms_as an ability to use relevant

Deleted:

Copy Editor 1/7/2018 3:28 PM

Deleted: Prior to

Copy Editor 1/7/2018 3:29 PM

Deleted: (Adult: Refusal of Treatment)

Copy Editor 1/7/2018 3:29 PM

Deleted: (

Copy Editor 1/7/2018 3:29 PM

Deleted: ) 
information in the process of deciding and have given some guidance to practitioners on how to do so (Owen, Freyenhagen, Martin, \& David, 2015). Our aim has been to help the law interpret abilities by drawing on cases where illumination is most likely to be found. We have done similarly with depression (Owen, Freyenhagen, \& Martin, 2015). Do these abilities tract authenticity? We would hope $\mathrm{so}_{2}$ but it is not our aim to introduce a new authenticity criterion to a legal test. Our aim is to specify abilities in extant legal tests and ground them in clinical phenomenology with a view to improving consistency and validity of DMC assessment.

\section{WISE DECISION}

A point made by Palmer on wise decision we think could do with some clarification on our part. Palmer cautions that "unwise decision" needs protection in brain injury cases because it could easily be understood as disagreeing with one's physician_thus, creating problems with respecting patient autonomy. We concur entirely. A principle of the Mental Capacity Copy Editor 1/7/2018 3:31 PM Deleted: Act is that "a person is not to be treated as unable to make a decision merely because he makes an unwise decision" (section 1(4)). A key motivation for our study is how this principle can be upheld in cases of brain injury where there is often unwise decision making. To us ${ }_{2}$ the answer has to lie in specifying the decision-making abilities and clarifying the distinction between an unwise decision made with the requisite abilities and one made without. We want to give assessors the tools to be able to distinguish, even in brain injury,

those two classes of possibility. It is a difficult problem, but we argue amenable to solutions.

\section{SUPPORTING DECISIONMAKING}

McMillan invites us to consider the question of how people with brain injury could be supported to make decisions for themselves_although he warns this could be another paper! Rather than venture into how neuropsychological rehabilitation aims to help people with brain injury compensate for their deficits__ both with psychological techniques but also with suitability adjusted environments and understanding from others $\Longrightarrow$ we will simply draw

\section{Copy Editor 1/7/2018 3:31 PM}

Deleted: -

Copy Editor 1/7/2018 3:31 PM

Deleted: hard

Copy Editor 1/7/2018 3:31 PM

Formatted: Small caps

Copy Editor 1/7/2018 3:31 PM

Deleted: -

Copy Editor 1/7/2018 3:31 PM

Deleted: $M$

Copy Editor 1/7/2018 3:31 PM

Formatted: Small caps

Copy Editor 1/7/2018 3:26 PM

Deleted: -

Copy Editor 1/7/2018 3:32 PM

Deleted: -

Copy Editor 1/7/2018 3:32 PM

Deleted: - 
attention to how the concept of extended mind may be approached in terms of extended decision-making community (Martin \& Hickerson, 2013). Putting an emphasis on the social aspects of practical reasoning and how communities can act to foster or hinder this reasoning is relevant to the extreme social disconnection patients with brain injury often find themselves in. For many (judges included), the decision-making community a person with brain injury is part of makes the difference between enough capability to make a meaningful decision and not enough.

But we also think some clarification is needed on our part. Part of our intention in this study is to probe what we are calling the "overlap problem." We framed this in terms of the impulsivity of decision making. This is often cited as a concern in people with brain injury. But, taken by itself, there is clearly an overlap between impulsivity in the general population and the population with brain injury. So if impulsive decision making is the basis of assessments of DMC in people with brain injury it looks like discrimination. What we hoped to show in the paper is that the impulsivity in the brain injury cases we report is of a distinctive kind and meaningfully connected to the loss of online awareness that we recommend putting at the center of DMC assessment in this group. If we are right in this contention $_{2}$ then the overlap problem disappears.

\section{Normativity}

Palmer's commentary provides us with a welcome opportunity to clarify our use of the term,

“normative," particularly in connection with our finding regarding patients' impaired ability to be alive to normative dimensions of the decision-situation. Palmer is correct in seeing a connection between the problems of normativity and issues regarding "patients' values or preferences," or what Palmer describes as the "difficulty some patients may have in assigning or applying valance to possible outcomes", (p. 000). <EQ? To clarify: We use "normative" to mean of or pertaining to norms, where by "norms" we have in mind a broad class of action-guiding considerations that includes values, principles of etiquette, standards 
of decency, epistemic virtues, and so on. Our key finding in this connection concerns the ways in which some ABI patients exhibited a real-time blindness to what we call the

"normative texture" of a decision situation - that is, to the extent to which their comportment either conformed or failed to conform to relevant norms of behavior - even though they were able to recognize that normative texture retrospectively.

As Palmer recognizes, this immediately raises the question of what makes a norm "relevant," which in turn brings back the thorny issues about authenticity. However, it is also important to recognize that one need not rely on some general analysis of authenticity to warrant a finding of impaired DMC where this distinctive form of normative blindness is exhibited. Consider the case of ABI2's use of offensive language. ABI2 reported that he recognized only retrospectively the extent to which his swearing and racist remarks caused offense, violating widely accepted norms of decency and causing distress for members of his care team. It would certainly not be correct to find that ABI2 lacked DMC as regards his use of language simply on the basis that his swearing violates community norms. That would be to revert to an objectionable outcome test. But do we need to know whether the norms of linguistic decency are ones that ABI 2 authentically embraces? We do not think so. What $\mathrm{ABI} 2$ himself reports is that he regrets his norm-violating behavior after the fact, but that in the real-time speech situation, ${ }_{2}$ he lacks effective awareness of the fact that his actions are violations of the relevant norms. That is enough to demonstrate that his DMC is impaired in those situations: He is blind to considerations that he himself recognizes to be relevant for navigating those situations in the way that he wants to. We might need assurances that this recognition is not the result of some serious brainwashing or coercion, but one need not invoke here the potentially more demanding and difficult-to-ascertain standard of authenticity.

\section{Fulford's Theory of MENTAL ILlness as ACTIONFAiLuRe}

McMillan invites us to clarify the relation between our findings and the model of mental
Deleted: -

Copy Editor 1/7/2018 3:26 PM

Deleted:

Copy Editor 1/7/2018 3:34 PM

Deleted: in order

Copy Editor 1/7/2018 3:34 PM

Deleted:

Copy Editor 1/7/2018 3:34 PM

Deleted:

Copy Editor 1/7/2018 3:34 PM

Deleted:

Copy Editor 1/7/2018 3:34 PM

Deleted: '

Copy Editor 1/7/2018 3:34 PM

Deleted:

Copy Editor 1/7/2018 3:34 PM

Deleted: -

Copy Editor 1/7/2018 3:34 PM

Deleted: -

Copy Editor 1/7/2018 3:35 PM

Deleted: he

Copy Editor 1/7/2018 3:35 PM

Formatted: Small caps

Copy Editor 1/7/2018 3:35 PM

Deleted: -

Copy Editor 1/7/2018 3:35 PM

Formatted: Small caps 
illness and insight that has been developed by Fulford in his 1989 book and a number of subsequent publications. A full discussion of this question would require a much fuller analysis of Fulford's position than is possible here. However, a few observations are in order. We consider ourselves to be in common cause with one of Fulford most fundamental claims, namely that mental illness should be considered not narrowly as a matter of cognitive failure, but as an impairment of practical rationality. For the patients in our study, it is imperative to recognize the variety of ways in which they may in a narrow sense know something about their impairments and nonetheless be unable to put that knowledge to work in action. In this respect, we agree with Fulford.

Having said this, however, we wish to enter two caveats about using our findings in support of Fulford's general claim that, as McMillan puts it, "there is a conceptual link" between mental illness and lack of insight. This is a claim that has a long history (Berrios \& Markova, 2004), but we believe that it should be approached with caution. One important class of counterexamples encountered in our own research comes with depression, where patients suffering from a mental illness often show a high degree of insight (Amador et al., 1994; Owen David, Hayward, \& Hotopf, 2009). At least as a starting point, then, we prefer to treat lack of insight as a variable in the population of patients with mental illness, treating the link as empirical rather than conceptual. Second, Fulford has proposed a particular analysis of the structure of loss of insight _ $\ldots$ what he refers to as the "misconstrual account of insight" (Fulford, 2004), according to which loss of insight consists in an inability of a patient to navigate a distinction among three classes of "happenings": things that $L_{\mathbf{z}}$ do, things, that happen to me, and things that are wrong. Fulford's model was explicitly developed in the first instance to capture the structure of the lack of insight in schizophrenia. We believe that caution is called for in extending this conceptualization of loss of insight to organic personality disorder, which was our focus in this study. This is a matter to which we hope to return in future work.

Copy Editor 1/7/2018 3:35 PM

Deleted: But

Copy Editor 1/7/2018 3:35 PM

Deleted: viz.

Copy Editor 1/7/2018 3:36 PM

Deleted: -

Copy Editor 1/7/2018 3:36 PM

Deleted: et al.

Copy Editor 1/7/2018 3:36 PM

Deleted: -

Copy Editor 1/7/2018 3:36 PM

Deleted: -

Copy Editor 1/7/2018 3:36 PM

Deleted: ly

Copy Editor 1/7/2018 3:36 PM

Deleted: -

Copy Editor 1/7/2018 3:36 PM

Deleted: -

Copy Editor 1/7/2018 3:36 PM

Deleted: (

Copy Editor 1/7/2018 3:37 PM

Deleted: -

Copy Editor 1/7/2018 3:37 PM

Deleted: -

Copy Editor 1/7/2018 3:37 PM

Deleted: -

Copy Editor 1/7/2018 3:37 PM

Deleted: -

Copy Editor 1/7/2018 3:37 PM

Deleted: -

Copy Editor 1/7/2018 3:37 PM

Deleted: -

Copy Editor 1/7/2018 3:37 PM

Deleted: -

Copy Editor 1/7/2018 3:37 PM

Deleted: -

Copy Editor 1/7/2018 3:37 PM

Deleted: -

Copy Editor 1/7/2018 3:37 PM

Deleted: -

Copy Editor 1/7/2018 3:37 PM

Deleted: -

Copy Editor 1/7/2018 3:37 PM

Deleted: -

Copy Editor 1/7/2018 3:37 PM

Deleted: -

Copy Editor 1/7/2018 3:37 PM

Deleted: - 


\section{References}

Adults with Incapacity (Scotland) Act. (2000).

Amador, X. F., Flaum, M., Andreasen, N._C., Strauss, D._H., Yale, S._A., Clark, S._C., \& Gorman, M. (1994). Awareness of illness in schizophrenia and schizoaffective and mood disorders. Archives of General Psychiatry, 51, 10, 826-836.

Berg, J. W., Appelbaum, P._S., \& Grisso, T. (1996). Constructing competence: Formulating standards of legal competence to make medical decisions. Rutgers Law Review, 48, $2,345-371$

Berrios, G. E., \& Markova, L._S. (2004). Insight and psychosis: a conceptual history. In X. F. Amador \& A. S. David (Eds.), Insight and Psychosis. Oxford: Oxford University Press.

Charland, L. C. (2011, Summer edition) Decision-making capacity. Stanford Encyclopedia of Philosophy. Available: http://plato.stanford.edu/entries/decision-capacity/.

Christman, J. (2009). The Politics of Persons: Individual Autonomy and Socio-historical Selves. Cambridge: Cambridge University Press.

Dworkin, G. (1976). Autonomy and behaviour çontrol. Hastings Center Report, 6, 1, 23-28.

Frankfurt, H. (1971). Freedom of the will and the concept of a person. Journal of Philosophy, 68, 1:5-20.

Fulford, K. W. M. (2004). Insight and delusion: From Jaspers to Kraeplin and back again via Austin. In X. F. Amador \& A._S. David (Eds.), Insight and Psychosis. Oxford University Press.

Martin, W., \& Hickerson, R. (2013). Mental capacity and the applied phenomenology of judgement. Phenomenology and the Cognitive Sciences, 12, 1, 195-214.

Copy Editor 1/7/2018 3:38 PM Deleted: B Copy Editor 1/7/2018 3:38 PM Deleted: C Copy Editor 1/7/2018 3:38 PM Deleted: The

Copy Editor 1/7/2018 3:39 PM Deleted: $\mathrm{W}$

Copy Editor 1/7/2018 3:39 PM Deleted: C

Copy Editor 1/7/2018 3:39 PM Deleted: $\mathrm{P}$ Copy Editor 1/7/2018 3:39 PM Deleted: The Copy Editor 1/7/2018 3:39 PM Deleted: from Copy Editor 1/7/2018 3:39 PM Deleted: Capacity Copy Editor 1/7/2018 3:39 PM Deleted: phenomenoloyg 
Owen, G. S., David, A._S., G., G., Hayward, P., \& Hotopf, M. (2009). Mental capacity, diagnosis and insight in psychiatric in-patients: A cross-sectional study.

Psychological Medicine, 39, 8, 1389-1398.

Owen, G. S., Freyenhagen, F., \& David, S. (2015). Clinical assessment of decision-making capacity in acquired brain injury with personality change. Neuropsychological Rehabilitation, 19, 1-16.

Owen, G. S., Freyenhagen, F., \& Martin, W. (2015). Temporal inabilities and decisionmaking capacity in depression. Phenomenology and the Cognitive Sciences, 15, Copy Editor 1/7/2018 3:39 PM

Deleted: $r$

Copy Editor 1/7/2018 3:39 PM

Deleted: [Epub ahead of print] $1: 163-182$.

Re C (Adult: Refusal of Treatment) [1994] 1 All ER 819.

The Law Commission. (1995). Mental Incapacity London: HMSO. 